\title{
Pengaruh Variasi Insulator Saluran Chilled Water Terhadap Performansi Prototype Mini Water Chiller
}

\author{
I G M. Buddhi Satya Utama*, I N. Pasek Nugraha, I G. Wiratmaja \\ Program Studi Pendidikan Teknik Mesin, Fakultas Teknik dan Kejuruan \\ Universitas Pendidikan Ganesha, Singaraja, Bali, Indonesia \\ *Penulis korespondensi: budisatya55@gmail.com
}

Histori artikel: diserahkan 21 Juli 2021, direviu 15 Agustus 2021, direvisi 14 September 2021

\begin{abstract}
The high heat transfer rate from the environment to the chilled water pipe will affect the performance of the mini water chiller prototype, so it is necessary to insulate the chilled water pipe using the right insulator to optimize the performance of the mini water chiller prototype. Therefore, this study aims to determine the effect of the chilled water pipe insulator variations: nitrile rubber expanded and polyurethane foam on the optimal temperature and cooling rate of the mini water chiller prototype cabin. The method used in this study is an experimental method with a variation of the insulator as independent variables and the optimal temperature also cooling rate of the mini water chiller prototype cabin as the dependent variables. The testing process was carried out 20 times repetition of data collection on each variation using a stopwatch, thermo gun, thermostat, ampere pliers, a bulb, and a water heating element as a tool in research. In addition, it expanded nitrile rubber and polyurethane foam spray as research material. The results obtained from this study showed that the average optimal temperature achievement of the mini water chiller prototype with polyurethane foam insulator was $11.242^{\circ} \mathrm{C}$, and with the nitrile rubber expanded insulator was $11.250^{\circ} \mathrm{C}$. Otherwise, the average cooling rate of the mini water chiller prototype cabin with polyurethane foam insulator variation was $0.001421^{\circ} \mathrm{C}$, while in the variation of nitrile rubber expanded it was $0.001032^{\circ} \mathrm{C}$, which indicates that there is an effect of chilled water pipe insulator variations on the performance of the mini water chiller prototype.
\end{abstract}

Keywords: Insulation, performance, prototype mini water chiller

DOI : https://doi.org/10.18196/jqt.v3i1.12264

WEB : https://journal.umy.ac.id/index.php/qt/article/view/12264

\section{PENDAHULUAN}

Teknologi mesin pendingin digunakan untuk berbagai kepentingan, seperti untuk penyimpanan bahan makanan, obat-obatan, zat-zat kimia, dll. Seiring berkembangnya zaman dan teknologi, penggunaan mesin pendingin juga dipergunakan dalam skala yang lebih besar yakni untuk mendinginkan suhu ruangan. Hal ini dilakukan demi tercapainya suhu ruangan yang nyaman untuk manusia dalam beraktifitas di dalam ruangan tersebut, seiring dengan meningkatnya suhu permukaan bumi yang diakibatkan oleh pemanasan global. Salah satu mesin pendingin ruangan yang telah banyak digunakan pada masa sekarang ini yakni water chiller. Water chiller banyak digunakan sebagai mesin pendingin dalam skala industri karena water chiller memiliki kelebihan dibandingkan dengan mesin pendingin ruangan lain seperti AC Split dan juga AC pada kabin kendaraan (refrigerant) dengan evaporator ganda yang telah diteliti oleh Purnomo et al. (2020) yaitu perawatan condensing unit yang terpusat pada satu tempat walaupun dengan jumlah evaporating unit yang banyak.

Water chiller merupakan mesin pendingin ruangan yang menggunakan media pendinginan berupa air bersuhu rendah yang disirkulasikan di dalam Air handling Unit (AHU) (Supriana et al., 2019; Kayana et al., 2019). Air bersuhu rendah yang digunakan dalam proses penurunan suhu ruangan dihasilkan dengan cara mendinginkan air menggunakan media refrigerant yang ditekan 
oleh kompresor. Air bersuhu rendah tersebut kemudian dipompa menuju AHU pada tiaptiap ruangan melalui sebuah saluran. Saluran tersebut kemudian disebut dengan saluran chilled water. Saluran chilled water merupakan komponen water chiller yang paling banyak terpapar oleh udara luar. Oleh sebab itu, insulasi saluran chilled water menjadi hal yang sangat penting baik dalam perencanaan maupun pengoperasian water chiller. Prototipe dari alat water chiller diberi nama mini water chiller. Alat tersebut dibuat untuk memudahkan proses pembelajaran maupun penelitian. Mini water chiller memiliki cara kerja yang sama dengan water chiller pada umumnya, namun dengan ukuran yang lebih kecil, dan tetap memiliki komponen yang lengkap sesuai dengan komponen penyusun water chiller. Komponen-komponen penyusunnya adalah kompresor, kondensor, evaporator, pompa, chilled water tank, saluran chilled water, dan AHU yang telah dirancang sedemikian rupa hingga ukurannya bisa dibuat lebih kecil.

Beberapa penelitian telah dilakukan untuk mengoptimalkan performansi Mini water chiller agar mendekati sempurna. Beragam penelitian yang telah dilakukan, belum terdapat penelitian yang berhubungan dengan insulasi saluran chilled water mini water chiller. Hal ini sangat disayangkan mengingat energi panas yang berasal dari lingkungan dapat berpindah ke saluran chilled water mini water chiller secara konveksi dengan cepat apabila saluran tersebut tidak terinsulasi, dan akhirnya akan terjadi kondensasi pada saluran tersebut yang mempengaruhi capaian suhu dan laju pendinginan pada kabin mini water chiller.

Efek kondensasi pada saluran chilled water dapat dikurangi dengan cara mengganti insulator saluran chilled water mini water chiller dengan insulator yang memiliki konduktivitas thermal yang rendah, misalnya nitrile rubber expanded dan polyurethane foam. Dalam penelitian ini, akan memvariasikan bahan insulasi saluran chilled water prototype mini water chiller untuk meningkatkan performansinya. Penelitian ini dilakukan untuk mengetahui pengaruh penggunaan nitrile rubber expanded yang memiliki nilai konduktivitas thermal sebesar $0.033-0.044 \mathrm{~W} / \mathrm{mK}$ dan polyurethane foam yang memiliki nilai konduktivitas thermal yang lebih rendah yakni $0,016-0,023 \mathrm{~W} / \mathrm{mK}$ (Deshmukh et al., 2017) sebagai bahan insulasi saluran chilled water prototype mini water chiller terhadap capaian suhu optimal dan laju pendinginan ruangan pada prototype mini water chiller.

\section{METODE}

Metode yang digunakan dalam penelitian ini adalah metode penelitian deskriptif kuantitatif. Variabel bebas dalam penelitian ini yakni variasi bahan insulasi saluran chilled water yang terdiri dari nitrile rubber expanded dan polyurethane foam, serta variabel terikat berupa capaian suhu optimal dan laju pendinginan prototype mini water chiller. Objek penelitian adalah bahan yang digunakan untuk menginsulasi saluran chilled water ptototype mini water chiller yaitu nitrile rubber expanded dan polyurethane foam, sedangkan subjek penelitian yaitu prototype mini water chiller yang ditunjukkan oleh Gambar 1.

Penelitian ini dilakukan melalui 3 (tiga) tahap yakni: tahap penyusunan alat penelitian; tahap penelitian; dan tahap pengolahan data. Tahap pertama yaitu penyusunan alat penelitian, dilakukan perubahan/modifikasi terhadap subjek penelitian untuk menyesuaikan keadaan subjek sesuai dengan hasil-hasil penelitian yang pernah dilakukan sebelumnya. Penyesuaian yang dilakukan diantarnya mengganti media pendingin kondensor dari pendingin udara menjadi pendingin air, mengganti pipa kapiler menggunakan pipa kapiler berdiameter 0,64 $\mathrm{mm}$ dengan panjang total $1 \mathrm{~m}$, dan mengganti air dalam chilled water supply tank dengan campuran air + coolant dengan perbandingan 1:1. Tahap kedua yaitu penelitian, dilakukan dengan cara mengamati perubahan suhu dalam kabin mini water chiller selama 20 menit dilakukan sebanyak 20 kali pada tiap variasi bahan insulasi saluran chilled water. Data yang didapat berupa suhu ruangan pendinginan (kabin) prototype mini water chiller. Pengolahan data menggunakan SPSS (Statistical Package for the Social Science) versi 20 untuk mengetahui pengaruh variasi insulator chilled water nitrile rubber expanded, dan polyurethane foam terhadap capaian suhu optimal dan laju pendinginan ruangan prototype mini water chiller. 

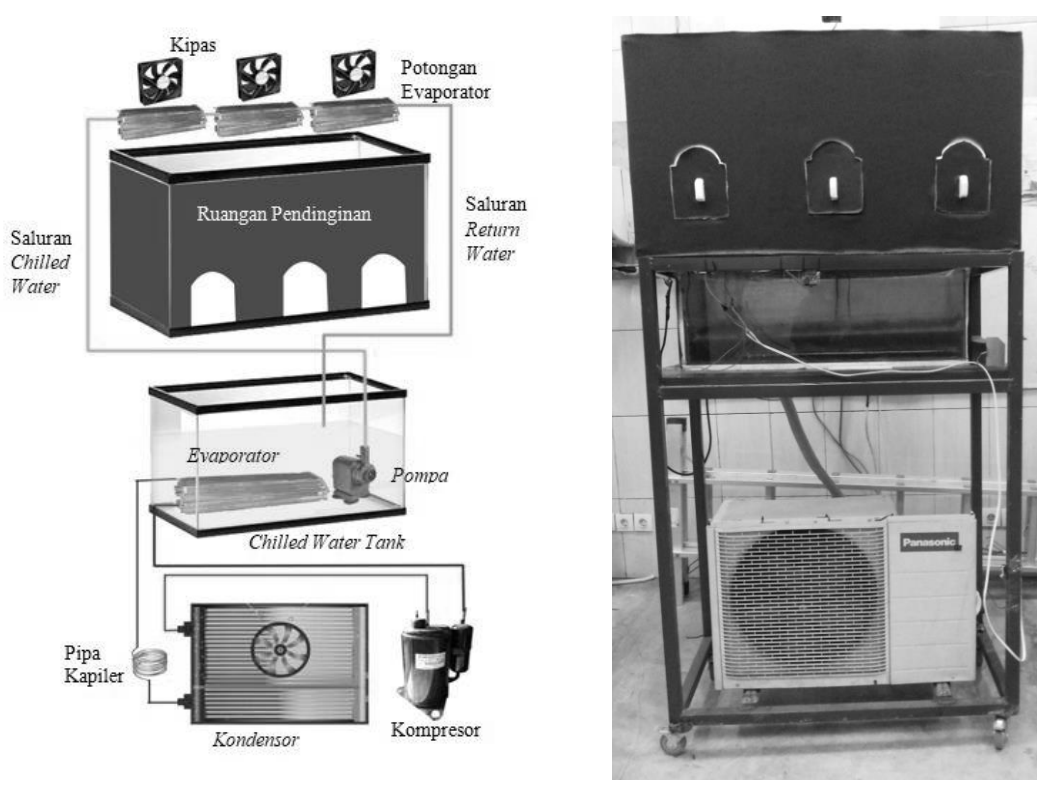

GAMBAR 1. Prototype Mini Water Chiller

\section{HASIL DAN PEMBAHASAN}

Setelah dilakukan pengujian sebanyak 20 kali pengulangan pada tiap variasi bahan insulasi saluran chilled water mini water chiller, didapatkan data capaian suhu optimal dan laju pendinginan kabin mini water chiller yang akan diuraikan di bawah.

\section{Data Hasil Pengujian Capaian Suhu Optimal}

Data capaian suhu optimal kabin prototype mini water chiller merupakan data suhu kabin terendah yang dapat dicapai oleh mini water chiller dengan variasi bahan insulasi saluran chilled water setelah 20 menit waktu kerja mini water chiller. Dari seluruh data yang telah didapatkan setelah 20 kali pengujian pada tiap variasi bahan insulasi saluran chilled water, didapati beberapa data memiliki selisih yang ekstrim sehingga data-data tersebut bersifat outlier. Data-data outlier perlu dieliminasi agar data menjadi normal. Setelah mengeliminasi sebanyak 8 data outlier, maka diperoleh 12 data capaian suhu optimal normal. Data capaian suhu optimal mini water chiller normal ditunjukkan oleh Tabel 1 dan rata-rata data capaian suhu optimal prototype mini water chiller ditunjukkan pada Gambar 2.
TABel 1. Data Capaian Suhu Optimal Prototype Mini Water Chiller

\begin{tabular}{ccc}
\hline \multirow{2}{*}{$\begin{array}{c}\text { Pengujian } \\
\text { ke- }\end{array}$} & \multicolumn{2}{c}{ Capaian Suhu Optimal $\left({ }^{\circ} \mathrm{C}\right)$} \\
\cline { 2 - 3 } & $\begin{array}{c}\text { Nitrile Rubber } \\
\text { Expanded }\end{array}$ & $\begin{array}{c}\text { Polyurethane } \\
\text { Foam }\end{array}$ \\
\hline 1 & 11,3 & 11,3 \\
\hline 2 & 11,2 & 11,3 \\
\hline 3 & 11,3 & 11,2 \\
\hline 4 & 11,3 & 11,2 \\
\hline 5 & 11,2 & 11,3 \\
\hline 6 & 11,2 & 11,2 \\
\hline 7 & 11,3 & 11,3 \\
\hline 8 & 11,3 & 11,2 \\
\hline 9 & 11,2 & 11,2 \\
\hline 10 & 11,2 & 11,2 \\
\hline 11 & 11,3 & 11,3 \\
\hline 12 & 11,2 & 11,2 \\
\hline
\end{tabular}

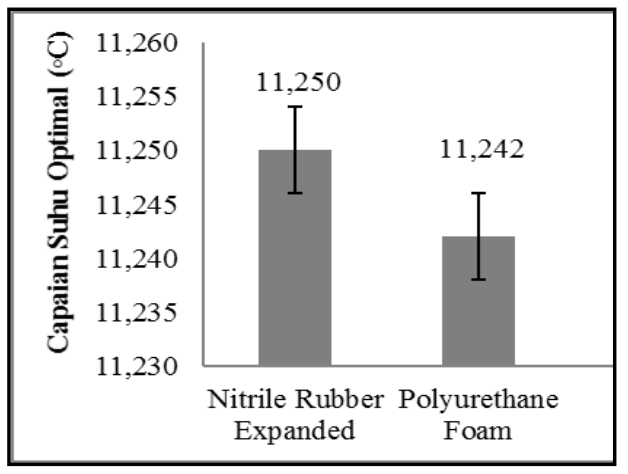

GAMBAR 2. Grafik Pengaruh Variasi Bahan Insulasi Saluran Chilled Water Terhadap Capaian Suhu Optimal Prototype Mini Water Chiller 
TABEL 2. Klasifikasi Data Capaian Suhu Optimal Variasi Bahan Insulasi Nitrile Rubber Expanded

\begin{tabular}{cccccc}
\hline No & Rentang Skor & Kelas Interval & Frekuensi & $\%$ & Kategori \\
\hline 1 & $\mathrm{Mi}+1,5 \mathrm{SDi} \leq \mathrm{x}$ & $11,28 \leq \mathrm{x}$ & 6 & 50 & Sangat Tinggi \\
\hline 2 & $\mathrm{Mi}+0,5 \mathrm{SDi} \leq \mathrm{x} \leq \mathrm{Mi}+1,5 \mathrm{SDi}$ & $11,26 \leq \mathrm{x} \leq 11,28$ & 0 & 0 & Tinggi \\
\hline 3 & $\mathrm{Mi}-0,5 \mathrm{SDi} \leq \mathrm{x} \leq \mathrm{Mi}+0,5 \mathrm{SDi}$ & $11,24 \leq \mathrm{x} \leq 11,26$ & 0 & 0 & Sedang \\
\hline 4 & $\mathrm{Mi}-1,5 \mathrm{SDi} \leq \mathrm{x} \leq \mathrm{Mi}-0,5 \mathrm{SDi}$ & $11,22 \leq \mathrm{x} \leq 11,24$ & 0 & 0 & Rendah \\
\hline 5 & $\mathrm{x} \leq \mathrm{Mi}-1,5 \mathrm{SDi}$ & $\mathrm{x} \leq 11,22$ & 6 & 50 & Sangat Rendah \\
\hline & & 12 & 100 & \\
\hline
\end{tabular}

TABeL 3. Klasifikasi Data Capaian Suhu Optimal Variasi Bahan Insulasi Polyurethane Foam

\begin{tabular}{cccccc}
\hline No & Rentang Skor & Kelas Interval & Frekuensi & $\%$ & Kategori \\
\hline 1 & $\mathrm{Mi}+1,5 \mathrm{SDi} \leq \mathrm{x}$ & $11,28 \leq \mathrm{x}$ & 5 & 41,7 & Sangat Tinggi \\
\hline 2 & $\mathrm{Mi}+0,5 \mathrm{SDi} \leq \mathrm{x} \leq \mathrm{Mi}+1,5 \mathrm{SDi}$ & $11,26 \leq \mathrm{x} \leq 11,28$ & 0 & 0 & Tinggi \\
\hline 3 & $\mathrm{Mi}-0,5 \mathrm{SDi} \leq \mathrm{x} \leq \mathrm{Mi}+0,5 \mathrm{SDi}$ & $11,24 \leq \mathrm{x} \leq 11,26$ & 0 & 0 & Sedang \\
\hline 4 & $\mathrm{Mi}-1,5 \mathrm{SDi} \leq \mathrm{x} \leq \mathrm{Mi}-0,5 \mathrm{SDi}$ & $11,22 \leq \mathrm{x} \leq 11,24$ & 0 & 0 & Rendah \\
\hline 5 & $\mathrm{x} \leq \mathrm{Mi}-1,5 \mathrm{SDi}$ & $\mathrm{x} \leq 11,22$ & 7 & 58,3 & Sangat Rendah \\
\hline & Jumlah & & 12 & 100 & \\
\hline
\end{tabular}

Hasil uji analisis statistik deskriptif kuantitatif dari data-data capaian suhu optimal prototype mini water chiller secara ringkas dijabarkan pada Tabel 2 dan Tabel 3. Berdasarkan hasil pengolahan data dan uji statistik, didapati bahwa capaian suhu optimal pada mini water chiller mengalami penurunan yang lebih besar pada saat saluran chilled water diinsulasi menggunakan polyurethane foam yang memiliki konduktivitas thermal sebesar 0,016 hingga $0,023 \mathrm{~W} / \mathrm{mK}$ dibandingkan dengan nitrile rubber expanded yang memiliki konduktivitas thermal sebesar $0.033-0.044$ $\mathrm{W} / \mathrm{mK}$.

Hal ini sejalan dengan hasil penelitian yang dilakukan oleh Muntolib \& Rusdiyantoro (2014) dan teori insulasi thermal yang dikemukakan oleh Deshmukh et al. (2017) yang menyatakan bahwa semakin rendah nilai konduktivitas thermal bahan insulasi maka laju perpindahan panas dari lingkungan ke sistem akan semakin rendah pula, sehingga air dingin yang mengalir di dalam saluran chilled water yang diinsulasi menggunakan polyurethane foam akan memiliki suhu yang lebih rendah pada saat memasuki FCU dibandingkan saat mengalir di dalam saluran chilled water yang diinsulasi menggunakan nitrile rubber expanded. Semakin rendah suhu air dingin yang masuk ke dalam FCU, maka kabin prototype mini water chiller pun dapat mencapai suhu yang lebih rendah dalam kurun waktu yang sama.

\section{Data Hasil Pengujian Laju Pendinginan Ruangan}

Laju pendinginan ruangan prototype mini water chiller merupakan besar energi kalor yang dapat dibuang oleh prototype mini water chiller per satuan waktu. Laju pendinginan ruangan prototype mini water chiller berbanding lurus dengan massa jenis udara, volume ruangan prototype mini water chiller, kalor spesifik udara, perbedaan suhu, dan berbanding terbalik dengan selang waktu. Pengambilan data dilakukan sebanyak 20 (dua puluh) kali pada tiap variasi bahan insulasi saluran chilled water selama 20 menit waktu kerja prototype mini water chiller. Data mentah yang didapat berupa selang waktu yang dibutuhkan oleh prototype mini water chiller untuk menurunkan suhu kabin dari $30^{\circ} \mathrm{C}$ menjadi $24^{\circ} \mathrm{C}$

Setelah mendapat data selang waktu untuk laju pendinginan ruangan prototype mini water chiller, selanjutnya dilakukan pengambilan data-data parameter yang dibutuhkan dalam perhitungan laju pendinginan ruangan prototype mini water chiller diantaranya massa jenis udara ( $\rho$ ), kalor spesifik udara $(\mathrm{Cp})$, volume kabin prototype mini water chiller (V), serta temperatur awal dan akhir kabin prototype mini water chiller. Rumus laju pendinginan ruangan ditunjukkan pada persamaan (1).

$\dot{q}_{u d}=\rho \cdot V \cdot C_{p^{x}} \frac{\text { Tawal-Takhir }}{\Delta t}$ 
dengan $\dot{q}_{\text {ud }}=$ laju pendinginan ruangan prototype mini water chiller $(\mathrm{kJ} / \mathrm{s}), \rho=$ massa jenis udara, $\mathrm{V}=$ volume ruangan pendinginan prototype mini water chiller, $\mathrm{Cp}=$ kalor spesifik udara, $\mathrm{T}_{\text {awal }}=$ suhu dalam ruangan pendinginan prototype mini water chiller awal, $\mathrm{T}_{\mathrm{akhir}}=$ suhu dalam ruangan pendinginan prototype mini water chiller akhir, dan $\Delta \mathrm{t}=$ selang waktu yang dibutuhkan oleh prototype mini water chiller untuk menurunkan suhu kabin dari $30^{\circ} \mathrm{C}$ menjadi $24^{\circ} \mathrm{C}$.
Dari seluruh data yang telah didapatkan setelah 20 kali pengujian pada tiap variasi bahan insulasi saluran chilled water, didapati beberapa data laju pendinginan ruangan memiliki selisih yang ekstrim sehingga datadata tersebut bersifat outlier. Data-data outlier perlu dieliminasi agar data menjadi normal. Setelah mengeliminasi sebanyak 8 data outlier, maka diperoleh 12 data capaian laju pendinginan ruangan normal, dan hasilnya dijabarkan pada tabel 4, 5, dan Gambar 3.

TABEL 4. Data Laju Pendinginan Ruangan Prototype Mini Water Chiller Variasi Bahan Insulasi Saluran Chilled Water Nitrile Rubber Expanded

\begin{tabular}{ccccccc}
\hline $\begin{array}{c}\text { Pengulangan } \\
\text { Pengujian }\end{array}$ & $\begin{array}{c}\text { Massa Jenis } \\
\text { udara }(\rho)\end{array}$ & $\begin{array}{c}\text { Volume } \\
\text { ruangan }\left(\mathrm{m}^{3}\right)\end{array}$ & $\begin{array}{c}\text { Temp. Awal } \\
\text { ruangan }\left({ }^{\circ} \mathrm{C}\right)\end{array}$ & $\begin{array}{c}\text { Temp. Akhir } \\
\text { ruangan }\left({ }^{\circ} \mathrm{C}\right)\end{array}$ & $\begin{array}{c}\text { Selang } \\
\text { waktu }(\mathrm{s})\end{array}$ & $\begin{array}{c}\text { Laju pendinginan } \\
\text { Ruangan }(\mathrm{kJ} / \mathrm{s})\end{array}$ \\
\hline 1 & 1,2 & 0,0495 & 30 & 24 & 348 & 0,001029 \\
\hline 2 & 1,2 & 0,0495 & 30 & 24 & 346 & 0,001035 \\
\hline 3 & 1,2 & 0,0495 & 30 & 24 & 347 & 0,001032 \\
\hline 4 & 1,2 & 0,0495 & 30 & 24 & 348 & 0,001029 \\
\hline 5 & 1,2 & 0,0495 & 30 & 24 & 346 & 0,001035 \\
\hline 6 & 1,2 & 0,0495 & 30 & 24 & 347 & 0,001032 \\
\hline 7 & 1,2 & 0,0495 & 30 & 24 & 348 & 0,001029 \\
\hline 8 & 1,2 & 0,0495 & 30 & 24 & 346 & 0,001035 \\
\hline 9 & 1,2 & 0,0495 & 30 & 24 & 347 & 0,001032 \\
\hline 10 & 1,2 & 0,0495 & 30 & 24 & 348 & 0,001029 \\
\hline 11 & 1,2 & 0,0495 & 30 & 24 & 346 & 0,001035 \\
\hline 12 & 1,2 & 0,0495 & 30 & 24 & 348 & 0,001029 \\
\hline
\end{tabular}

TABEL 5. Data Laju Pendinginan Ruangan Prototype Mini Water Chiller Variasi Bahan Insulasi Saluran Chilled Water Polyurethane Foam

\begin{tabular}{ccccccc}
\hline $\begin{array}{c}\text { Pengulangan } \\
\text { Pengujian }\end{array}$ & $\begin{array}{c}\text { Massa Jenis } \\
\text { udara }(\rho)\end{array}$ & $\begin{array}{c}\text { Volume } \\
\text { ruangan }\left(\mathrm{m}^{3}\right)\end{array}$ & $\begin{array}{c}\text { Temp. Awal } \\
\text { ruangan }\left({ }^{\circ} \mathrm{C}\right)\end{array}$ & $\begin{array}{c}\text { Temp. Akhir } \\
\text { ruangan }\left({ }^{\circ} \mathrm{C}\right)\end{array}$ & $\begin{array}{c}\text { Selang } \\
\text { waktu }(\mathrm{s})\end{array}$ & $\begin{array}{c}\text { Laju pendinginan } \\
\text { Ruangan }(\mathrm{kJ} / \mathrm{s})\end{array}$ \\
\hline 1 & 1,2 & 0,0495 & 30 & 24 & 251 & 0,001427 \\
\hline 2 & 1,2 & 0,0495 & 30 & 24 & 252 & 0,001421 \\
\hline 3 & 1,2 & 0,0495 & 30 & 24 & 252 & 0,001421 \\
\hline 4 & 1,2 & 0,0495 & 30 & 24 & 252 & 0,001421 \\
\hline 5 & 1,2 & 0,0495 & 30 & 24 & 253 & 0,001416 \\
\hline 6 & 1,2 & 0,0495 & 30 & 24 & 253 & 0,001421 \\
\hline 7 & 1,2 & 0,0495 & 30 & 24 & 251 & 0,001416 \\
\hline 8 & 1,2 & 0,0495 & 30 & 24 & 253 & 0,001416 \\
\hline 1 & 1,2 & 0,0495 & 30 & 24 & 2527 \\
\hline 11 & 1,2 & 0,0495 & 30 & 24 & 253 & 0,001421 \\
\hline 12 & 1,2 & 0,0495 & 30 & 24 & 251 & 0,001416 \\
\hline
\end{tabular}

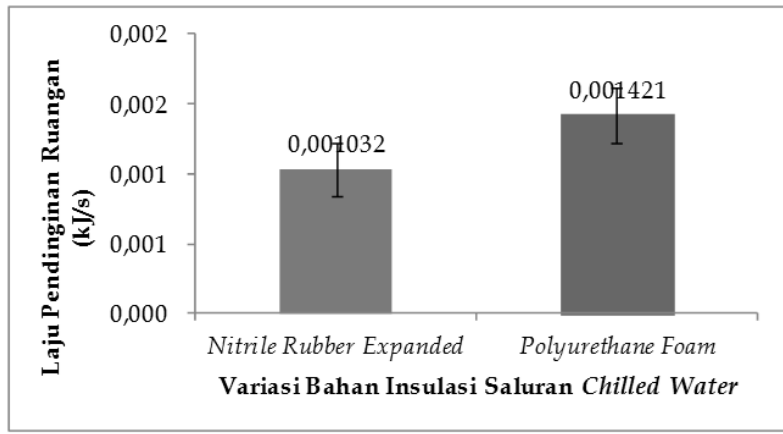

GAmbAR 3. Grafik Pengaruh Variasi Bahan Insulasi Terhadap Laju Pendinginan Ruangan 
TABEL 6. Klasifikasi Data Laju Pendinginan Ruangan Variasi Bahan Insulasi Nitrile Rubber Expanded

\begin{tabular}{cccccc}
\hline No & Rentang Skor & Kelas Interval & Frekuensi & $\%$ & Kategori \\
\hline 1 & $\mathrm{Mi}+1,5 \mathrm{SDi} \leq \mathrm{x}$ & $0,0010335 \leq \mathrm{x}$ & 4 & 33,3 & Sangat Tinggi \\
\hline 2 & $\mathrm{Mi}+0,5 \mathrm{SDi} \leq \mathrm{x} \leq \mathrm{Mi}+1,5 \mathrm{SDi}$ & $0,0010325 \leq \mathrm{x} \leq 0,0010335$ & 3 & 25 & Tinggi \\
\hline 3 & $\mathrm{Mi}-0,5 \mathrm{SDi} \leq \mathrm{x} \leq \mathrm{Mi}+0,5 \mathrm{SDi}$ & $0,0010315 \leq \mathrm{x} \leq 0,0010325$ & 0 & 0 & Sedang \\
\hline 4 & $\mathrm{Mi}-1,5 \mathrm{SDi} \leq \mathrm{x} \leq \mathrm{Mi}-0,5 \mathrm{SDi}$ & $0,0010305 \leq \mathrm{x} \leq 0,0010315$ & 0 & 0 & Rendah \\
\hline 5 & $\mathrm{x} \leq \mathrm{Mi}-1,5 \mathrm{SDi}$ & $\mathrm{x} \leq 0,0010305$ & 5 & 41,7 & Sangat Rendah \\
\hline & Jumlah & & 12 & 100 & \\
\hline
\end{tabular}

TABEL 7. Klasifikasi Data Laju Pendinginan Ruangan Variasi Bahan Insulasi Polyurethane Foam

\begin{tabular}{cccccc}
\hline No & Rentang Skor & Kelas Interval & Frekuensi & $\%$ & \multicolumn{2}{c}{ Kategori } \\
\hline 1 & $\mathrm{Mi}+1,5 \mathrm{SDi} \leq \mathrm{x}$ & $0,001425 \leq \mathrm{x}$ & 3 & 25 & Sangat Tinggi \\
\hline 2 & $\mathrm{Mi}+0,5 \mathrm{SDi} \leq \mathrm{x} \leq \mathrm{Mi}+1,5 \mathrm{SDi}$ & $0,001423 \leq \mathrm{x} \leq 0,001425$ & 0 & 0 & Tinggi \\
\hline 3 & $\mathrm{Mi}-0,5 \mathrm{SDi} \leq \mathrm{x} \leq \mathrm{Mi}+0,5 \mathrm{SDi}$ & $0,001421 \leq \mathrm{x} \leq 0,001423$ & 5 & 41,7 & Sedang \\
\hline 4 & $\mathrm{Mi}-1,5 \mathrm{SDi} \leq \mathrm{x} \leq \mathrm{Mi}-0,5 \mathrm{SDi}$ & $0,001419 \leq \mathrm{x} \leq 0,001421$ & 0 & 0 & Rendah \\
\hline 5 & $\mathrm{x} \leq \mathrm{Mi}-1,5 \mathrm{SDi}$ & $\mathrm{x} \leq 0,001419$ & 4 & 33,3 & Sangat Rendah \\
\hline & Jumlah & 12 & 100 & \\
\hline
\end{tabular}

Hasil uji analisis statistik deskriptif kuantitatif dari data-data laju pendinginan ruangan prototype mini water chiller secara ringkas dijabarkan pada Tabel 6 dan Tabel 7. Berdasarkan hasil pengolahan data dan uji statistik, didapati bahwa laju pendinginan ruangan prototype mini water chiller mengalami peningkatan yang lebih besar pada saat saluran chilled water diinsulasi menggunakan polyurethane foam yang memiliki konduktivitas thermal sebesar 0,016 hingga $0,023 \mathrm{~W} / \mathrm{mK}$ dibandingkan dengan nitrile rubber expanded yang memiliki konduktivitas thermal sebesar $0.033-0.044$ $\mathrm{W} / \mathrm{mK}$.

Hal ini sejalan dengan hasil penelitian yang dilakukan oleh Muntolib \& Rusdiyantoro (2014) dan teori insulasi thermal yang dikemukakan oleh Deshmukh et al. (2017) yang menyatakan bahwa semakin rendah nilai konduktivitas thermal bahan insulasi maka laju perpindahan panas dari lingkungan ke sistem akan semakin rendah pula, sehingga air dingin yang mengalir di dalam saluran chilled water yang diinsulasi menggunakan polyurethane foam akan memiliki suhu yang lebih rendah pada saat memasuki FCU dibandingkan saat mengalir di dalam saluran chilled water yang diinsulasi menggunakan nitrile rubber expanded. Semakin rendah suhu air dingin yang masuk ke dalam FCU, maka semakin cepat waktu yang dibutuhkan oleh kabin prototype mini water chiller untuk mencapai suhu $24^{\circ} \mathrm{C}$. Hal ini sesuai dengan rumus perhitungan yang menyatakan bahwa selang waktu berbanding terbalik dengan laju pendinginan, di mana semakin kecil selang waktu yang dibutuhkan oleh prototype mini water chiller untuk mencapai suhu $24^{\circ} \mathrm{C}$, maka laju pendinginan nya pun semakin besar.

\section{KESIMPULAN}

Terdapat pengaruh variasi bahan insulasi saluran chilled water nitrile rubber expanded dan polyurethane foam terhadap capaian suhu optimal prototype mini water chiller, dimana capaian suhu prototype mini water chiller lebih optimal pada saat saluran chilled water diinsulasi menggunakan polyurethane foam dibandingkan dengan pada saat diinsulasi menggunakan nitrile rubber expanded. Terdapat pengaruh variasi bahan insulasi saluran chilled water nitrile rubber expanded dan polyurethane foam terhadap laju pendinginan ruangan prototype mini water chiller, dimana laju pendinginan ruangan prototype mini water chiller lebih tinggi pada saat saluran chilled water diinsulasi menggunakan polyurethane foam dibandingkan dengan saat saluran chilled water diinsulasi menggunakan nitrile rubber expanded. 


\section{DAFTAR PUSTAKA}

Deshmukh, G., Birwal, P., Datir, R., \& Patel, S. 2017. Thermal insulation materials: A tool for energy conservation. Journal of Food Processing \& Technology, 8(04), 15.

Kayana, M. D., Nugraha, I. N. P., \& Dantes, K. R. 2019. Analisa Pengaruh Laju Aliran Fluida Air pada Saluran Pipa AHU (Air Handling Unit) terhadap Capaian Suhu Optimum Mesin Pendingin Mini Water Chiler. Jurnal Pendidikan Teknik Mesin Undiksha, 7(3), 129-134.

Muntolib, \& Rusdiyantoro. 2014. Analisa Bahan Isolasi Pipa Saluran Uap Panas Pada Boiler untuk Meminimalisasi Heat Loss. Jurnal Teknik WAKTU, 12(02), 5056.

Purnomo, B. C., Widodo, N., Munahar, S., \& Nugroho, D. 2020. Karakteristik Refrigeran Musicool Dalam Mesin Refrigerasi Kompresi Uap Menggunakan Evaporator Ganda. Quantum Teknika: Jurnal Teknik Mesin Terapan, 1(2), 48-54.

Supriana, P. D., Dantes, K. R., \& Nugraha, I. N. P. 2019. Pengaruh Variasi Fluida Pendingin terhadap Capaian Suhu Optimal pada Rancangan Mesin Pendingin Mini Water Chiller. Jurnal Pendidikan Teknik Mesin Undiksha, 7(1), 36-42. 